\title{
STANDARD OF CARE, INSTITUTIONAL OBLIGATIONS, AND DISTRIBUTIVE JUSTICE
}

\section{DOUGLAS MACKAY}

\section{Keywords}

standard of care, institutional obligations, distributive justice

\begin{abstract}
The problem of standard of care in clinical research concerns the level of treatment that investigators must provide to subjects in clinical trials. Commentators often formulate answers to this problem by appealing to two distinct types of obligations: professional obligations and natural duties. In this article, I investigate whether investigators also possess institutional obligations that are directly relevant to the problem of standard of care, that is, those obligations a person has because she occupies a particular institutional role. I examine two types of institutional contexts: (1) public research agencies - agencies or departments of states that fund or conduct clinical research in the public interest; and (2) private-for-profit corporations. I argue that investigators who are employed or have their research sponsored by the former have a distinctive institutional obligation to conduct their research in a way that is consistent with the state's duty of distributive justice to provide its citizens with access to basic health care, and its duty to aid citizens of lower income countries. By contrast, I argue that investigators who are employed or have their research sponsored by private-forprofit corporations do not possess this obligation nor any other institutional obligation that is directly relevant to the ethics of RCTs. My account of the institutional obligations of investigators aims to contribute to the development of a reasonable, distributive justice-based account of standard of care.
\end{abstract}

The problem of standard of care in clinical research concerns the level of treatment that investigators must provide to subjects in clinical trials. Commentators often formulate answers to this problem by appealing to two distinct types of obligations. First, they appeal to professional obligations, that is, the obligations investigators possess insofar as they occupy a particular professional role. The 'best current proven intervention' standard of the Declaration of Helsinki ${ }^{1}$ is thus often thought to be an implication of investigators' therapeutic obligation, which

\footnotetext{
${ }^{1}$ World Medical Association. 2008. Declaration of Helsinki - Ethical Principles for Medical Research Involving Human Subjects. Available at: http://www.wma.net/en/30publications/10policies/b3/index .html [Accessed 3 Oct 2012].
}

they possess qua physicians. ${ }^{2}$ Second, they appeal to natural duties, that is, the duties investigators possess simply because they are persons. For example, some argue that investigators ought to provide subjects with effective treatment - as opposed to placebo - since they possess a duty of rescue qua persons. ${ }^{3}$

In this article, I investigate whether investigators also possess institutional obligations that are directly relevant to the problem of standard of care, that is, those

\footnotetext{
${ }^{2}$ See Marcia Angell. The Ethics of Clinical Research in the Third World. N Engl J Med 1997; 337: 847-849.

${ }^{3}$ See J. Hawkins. 2008. Exploitation and Placebo Controls. in Exploitation and Developing Countries: The Ethics of Clinical Research. J.S. Hawkins \& E.J. Emanuel, eds. Princeton: Princeton University Press: 260-266.
} 
obligations a person has because she occupies a particular institutional role. Like professional obligations therefore, institutional obligations are a species of role obligation the 'sort of obligation we have (or take ourselves to have) as occupants of social roles: as citizens, family members, teachers and so forth. ${ }^{34}$ However, for institutional obligations, the role in question is not a professional one - e.g. physician, teacher, or lawyer - but rather an institutional one - e.g. state official. By developing an account of investigators' institutional obligations in this way, I hope to shed some light on a significant normative dimension of the ethics of randomized controlled trials (RCTs) that has thus far been overlooked. By only appealing to investigators' professional obligations or natural duties, commentators have presupposed that investigators are simply moral freelancers, their institutional role irrelevant with respect to the moral norms that bind them.

I examine two types of institutional contexts: (1) public research agencies - agencies or departments of states that fund or conduct clinical research in the public interest; and (2) private-for-profit corporations. I argue that investigators who are employed or have their research sponsored by the former have a distinctive institutional obligation to conduct their research in a way that is consistent with the state's duty of distributive justice to provide its citizens with access to basic health care, and its duty to aid citizens of lower income countries. These investigators possess this duty because the state may not authorize its agents to act in ways that are inconsistent with its obligations. By contrast, I argue that investigators who are employed or have their research sponsored by private-for-profit corporations do not possess this obligation or any other institutional obligation that is directly relevant to the question of standard of care. Instead, these investigators are only bound by the professional obligations that apply to them, and their natural duties.

My discussion of institutional obligations has important implications for the problem of standard of care. Critics have argued quite convincingly that the professional obligations of investigators qua physicians do not provide an appropriate basis for developing an account of the ethics of RCTs. ${ }^{5}$ The investigator-subject relation, these critics argue, simply could not be subject to the same norms as the physician-patient relation because of the way in which the project of clinical research is distinct from the project of clinical care. ${ }^{6}$ In response, commen-

\footnotetext{
${ }^{4}$ M.O. Hardimon. Role Obligations. J Philos 1994; 91: 333-363: 333.

${ }^{5}$ See F.G. Miller and H. Brody. A Critique of Clinical Equipoise: Therapeutic Misconception in the Ethics of Clinical Trials. Hastings Cent Rep 2003; 33: 19-28; and E. Haavi Morreim. The Clinical Investigator as Fiduciary: Discarding a Misguided Idea. $J$ Law Med Ethics 2005; 33: 586-598.

${ }^{6}$ The purpose of research, after all, is to produce clinically relevant, generalizable knowledge, not to benefit particular individuals; and its
}

tators have increasingly appealed to considerations of distributive justice to provide a suitable account of what investigators owe to subjects. ${ }^{7}$ On these distributive justice-based accounts, investigators ought to provide subjects in the control arm with the treatment they are entitled to as a matter of distributive justice, and may only give subjects an experimental treatment if it is in a state of clinical equipoise with it.

Although I think that this is a more promising strategy, these accounts require further development. First, defenders of these accounts have not adequately shown why investigators must provide subjects with the care they are entitled to. After all, even if individuals are entitled to a particular treatment, it does not follow that investigators have a correlative duty to provide it to them. Second, defenders of these accounts have not adequately considered what investigators owe to their subjects in non-ideal conditions. May they conduct a RCT (1) that is necessary to develop a promising, affordable intervention, but (2) that requires providing subjects with care that is inferior to the care they are entitled to?

I show below that my account of investigators' institutional obligations helps to address these two shortcomings. In doing so, I hope to contribute to the development of a reasonable distributive justice-based account of standard of care.

\section{CLINICAL RESEARCH AND PUBLIC RESEARCH AGENCIES}

Public research agencies (PRAs) are agencies or departments of states responsible for funding and conducting clinical research in the public interest. In this part of the paper, I specify the institutional obligations of investigators working for two types of PRAs, each distinguished by the public in whose interest it funds and conducts research. Domestically-focused public research agencies (DPRAs) fund and conduct biomedical research to improve the care available to citizens. I will refer to investigators who are employed, or have their research funded, by these institutions as domestically-focused public research investigators (DPRIs). Internationally-focused public research agencies (IPRAs) fund or conduct research for the purposes of improving care available to those who reside in other countries. I will refer to investigators who are employed, or have their research funded,

methods reflect this purpose, including many procedures that offer no therapeutic benefit to subjects but that are necessary for scientific validity.

${ }^{7}$ See Rebecca Kukla. Resituating the Principle of Equipoise: Justice and Access to Care in Non-Ideal Conditions. Kennedy Inst Ethics $J$ 2007; 171-202; and Ezekiel J. Emanuel. 2012. Global Justice and the 'Standard of Care' Debates. in Global Justice and Bioethics. J. Millum \& E. Emanuel, eds. New York: Oxford University Press: 181-212. 
by these institutions as internationally-focused public research investigators (IPRIs). ${ }^{8}$

To determine the institutional obligations of investigators working for public research agencies and, as I discuss below, private-for-profit corporations, I rely on an account of the duties of public and private institutions within a liberal democracy which I will refer to as generic liberalism. Generic liberalism is a family of claims that (1) most, if not all, liberal political theories support, and (2) most, if not all, liberal democracies institutionalize or aspire to institutionalize. Generic liberalism thus aims to identify those claims that any reasonable theory of liberalism supports and that most citizens of liberal democracies understand to be normative for their societies. It therefore contrasts with specific liberal theories, for example, John Rawls's justice as fairness or Ronald Dworkin's liberal egalitarianism. I ground the institutional obligations of investigators in this way both to avoid debates amongst political philosophers that are irrelevant to my project; and to formulate an account that provides ethical guidance to investigators, given the institutional contexts within which they currently work. In what follows, I rely on five claims of generic liberalism:

1. Competent citizens possess a right to autonomy.

2. States have a duty of distributive justice to provide their citizens with access to basic health care.

3. States may fund biomedical research for the purposes of improving their citizens' health.

4. Higher income states have a duty to aid lower income states.

5. States may permit the formation of private-for-profit corporations and establish markets within which they may compete; private-for-profit corporations may seek profits within certain constraints.

I discuss each of these claims in greater detail below.

\subsection{Domestically-focused public research investigators}

DPRAs have the mandate of funding and conducting research to improve the care available to citizens. According to generic liberalism, the use of public resources for this purpose is justifiable to citizens because of the special significance of health for free persons concerned to set and pursue their own projects. Unlike cars or laptops, which persons require to set and pursue particular plans of life, a healthy body and mind constitutes all-purpose means necessary for setting and pursuing a

\footnotetext{
${ }^{8}$ DPRAs and IPRAs need not be different institutions. The NIH funds and conducts research aimed at improving the care available to both citizens and foreigners and so operates as both a DPRA and IPRA. USAID, by contrast, whose activity is focused on improving the health of foreigners, is a pure example of an IPRA.
}

plurality of plans of life. Public funding of biomedical research should therefore be acceptable to even those liberals who accept the principle of liberal neutrality, according to which states cannot justify their actions by appeal to a particular plan of life, but must do so by appeal to the more fundamental interest of citizens in setting and pursuing that plan of life that they deem best. ${ }^{9}$ As a factual matter, moreover, most liberal democracies publicly fund biomedical research.

Because DPRIs are agents of the state, carrying out the public mandate of conducting research in the public interest, they must conduct their research in a way that is consistent with the state's duties to its citizens. DPRIs must do so because states may not authorize their agents to treat their citizens in ways that are inconsistent with their duties to them. If the state owes its citizens X, it may not act in ways that are inconsistent with providing its citizens with $\mathrm{X}$, nor may it authorize its agents to do so.

To see this, suppose that A is the chief executive officer of state Y's ministry of transport. Suppose also that the state has a duty of justice to ensure that all employers observe a set of labour standards but that Y's ministry of labour fails to fully carry out this duty because of political corruption. Even though A's employees at the ministry of transport cannot expect any other employer to observe these standards, A nonetheless has a duty to ensure that the ministry of transport complies with them. A does not have to use the resources of her ministry to encourage other employers to comply with these standards; however, as an agent of the state, she must carry out her ministry's mandate in a way that is consistent with these duties.

Of particular importance for clinical research is the state's duty of distributive justice to provide its citizens with access to basic health care. States possess this duty because of the special significance of health for citizens considered as free persons concerned to set and pursue their own projects. ${ }^{10}$ This duty is widely supported by different theories of liberalism; ${ }^{11}$ also, liberal democracies, without exception, take the health of their citizens to be the responsibility of the state, by for example providing vaccinations, enforcing health and safety standards, or providing citizens with access to medical interventions. Fulfillment of this duty involves ensuring that all citizens

\footnotetext{
${ }^{9}$ See W. Kymlicka. Liberal Individualism and Liberal Neutrality. Ethics 1989; 99: 885-886.

${ }^{10}$ By basic health care here, I mean those public health initiatives and medical interventions - including personal medical services, preventive care, and public health measures - that are necessary if citizens are to maintain themselves as normally functioning, autonomous persons. N. Daniels. 1985. Just Health Care. New York: Cambridge University Press: ix.

${ }^{11}$ See Daniels, op. cit. note 10; and R. Dworkin. 2000. Sovereign Virtue: The Theory and Practice of Equality. Cambridge MA: Harvard University Press.
} 
have a permissible option - i.e. an option that it is permissible to take up - to access the treatments that constitute basic health care.

To conduct their research in a way that is consistent with this duty, DPRIs must not conduct their research in ways that preclude the state from fulfilling it. Since fulfillment involves ensuring that all citizens have a permissible option to receive the treatments they are entitled to, DPRIs preclude the state from fulfilling this duty when they enroll subjects in a RCT in which subjects receive a treatment that is ex ante inferior to the treatment that they are entitled to and would otherwise choose. For subjects enrolled in trials such as these, receiving the care they are entitled to is no longer a permissible option since they are bound by the protocol to receive a treatment that is ex ante inferior. In many cases, receiving the treatment they are entitled to will not be an option at all since participation in a trial will render treatments received outside of the trial less effective. By conducting such trials therefore, DPRIs preclude the state from fulfilling its duty to its citizens to provide them with access to basic health care.

DPRIs do not have to adopt the goal of providing all citizens with access to basic health care. However, just as $\mathrm{A}$, in the course of carrying out the mandate of the ministry of transport, must treat her employees in a way that is consistent with the state's duty to enforce certain labour standards, so too, DPRIs, in the course of carrying out their research, must treat their subjects in a way that is consistent with the state's duty to provide its citizens with access to basic health care. This obligation is an institutional obligation since DPRIs are bound by it because of the institutional role they occupy, namely, that of carrying out the state's mandate of conducting research to improve the care available to its citizens.

One might argue here that the only institutional duties investigators have are those that have been explicitly imposed by the institution in question, for example, in the form of institutionally-enacted policies. On this view, then, DPRIs only have a duty to conduct their research in a way that is consistent with the state's duty of distributive justice if the state or DPRA in question has said so. ${ }^{12}$

In response, let me note that I do not deny that institutional agents do have a duty to comply with the rules and procedures of their respective institutions, provided that they have been legitimately imposed. I do deny however that such rules and procedures are the only source of institutional obligations. As I discuss above, institutions such as states possess duties of justice. To claim that legitimately imposed rules and procedures are the only source of institutional obligations for agents would be to deny that these duties of justice bind institutional agents in any way. Of course there may be cases

${ }^{12}$ Thanks to an anonymous reviewer for pressing this objection. where there are conflicts between an agent's explicitly imposed obligations and those she possesses as a matter of justice. However, it doesn't follow from this that the latter do not exist or are not morally weighty. Instead, the institutional obligations agents possess as a matter of justice provide: (1) norms for designing institutional rules and procedures in the first place; (2) principles for interpreting rules and procedures when they are vague; and (3) pro tanto reasons for action.

What are the implications of DPRIs' institutional obligations under ideal and non-ideal conditions? Under ideal conditions, that is, conditions under which the state provides its citizens with access to the care they are entitled to, DPRIs have the following set of institutional obligations:

1. DPRIs may test a novel treatment on human subjects only if either:

a. it is in a state of clinical equipoise with, or known to be superior to, the best treatment that the state owes them; or

b. subjects autonomously prefer it to the treatments that the state owes them.

2. DPRIs ought to provide subjects in the control arm with either:

a. the best treatment that the state owes them; or

b. in cases where subjects autonomously reject (2a), the best treatment they:

i. will consent to; and

ii. are entitled to.

Note that this set of obligations does not require that DPRIs ensure that all subjects receive the best treatment they are entitled to or one that is in a state of clinical equipoise with it. Some might choose to accept less for altruistic reasons or because they are paid to do so. Because citizens have a right to autonomy and so are entitled to govern their own lives, states only have a duty to provide their citizens with access to basic health care, not to ensure that citizens in fact access it. DPRIs may therefore conduct RCTs that do not provide all subjects with the best treatment they are entitled to in full compliance with their institutional obligations provided that (1) their subject have access to it; and (2) their subjects autonomously prefer to forego accessing it. ${ }^{13}$ DPRIs need only avoid taking the inability of their subjects to access the treatments they are entitled to as a reason for providing them with less in the context of a RCT.

DPRIs may also test a novel treatment on subjects even if they know that it is superior to the treatment that the state owes them. The idea here is that DPRIs - at most only have an institutional obligation to provide their subjects with the treatment they are entitled to. If there is

\footnotetext{
${ }^{13}$ Of course, it may be that DPRIs possess professional obligations or natural duties that prohibit them from conducting such trials. Thanks to an anonymous reviewer for pointing this out.
} 
some new treatment $\mathrm{A}$ that is known to be superior to $\mathrm{B}$ (the treatment citizens are currently entitled to), but that is too expensive for the state to provide to all even if it were fully just, DPRIs are permitted to conduct RCTs evaluating $\mathrm{A}$ against $\mathrm{B}$ (for example, to determine its degree of superiority), even if $\mathrm{A}$ is known to be better than $\mathrm{B}^{14}$

Under non-ideal conditions, that is, conditions under which the state does not provide its citizens with access to the treatments to which they are entitled, things are more complicated. Consider rotacheap:

Rotacheap: Tazia is a lower income country ravaged by rotavirus, killing one of every 150 children. If Tazia were reasonably just, it could afford to provide each of its children with an effective rotavirus vaccine that is commercially available - Rotamax. However, because it is unjust - its political institutions are unrepresentative and its political elites are corrupt - the ministry of public health cannot afford to do so. Roberts, a DPRI, develops a promising vaccine - Rotamin - that, though less effective than Rotamax, is nonetheless affordable. She proposes a phase III placebo-controlled trial involving 50,000 children to evaluate the effectiveness of Rotamin.

Rotacheap satisfies neither of the institutional obligations I outline above. Rotamin is not in a state of clinical equipoise with Rotamax, the treatment that citizens are entitled to, and there is no reason to think they would prefer the former to the latter; and the trial involves giving subjects in the control arm a placebo, not Rotamax. One might conclude therefore that Roberts ought not to conduct rotacheap. Not so.

Consider first that Tazia wrongs the subjects in rotacheap by making and carrying out - by means of its agent Roberts - a coercive proposal. By a coercive proposal here, I mean a proposal that $\mathrm{X}$ makes to $\mathrm{Y}$ that (1) promises to make or leave $Y$ worse off than she has a right to be if she does not accept X's proposal (where Y's right is a claim right against $\mathrm{X}$ ), and (2) leaves $\mathrm{Y}$ no reasonable choice but to accept X's proposal. ${ }^{15}$ Tazia's proposal to its citizens is coercive in this way since (1) citizens of Tazia will be worse off than they have a right - against Tazia - to be if they do not participate in the trial, and (2) they - or in this case their surrogates - have no reasonable choice but to participate in the trial since it is the only way for them to secure a vaccine against a serious illness.

\footnotetext{
${ }^{14}$ Again, it may be that DPRIs possess professional obligations or natural duties that prohibit them from conducting such trials. My aim here is only to spell out the implications of DPRIs' institutional obligations, not to specify what they ought to do, all things considered.

${ }^{15}$ Alan Wertheimer. 1987. Coercion. Princeton: Princeton University Press: 202-221.
}

Roberts is complicit in this wrong since qua DPRI, she is an agent of Tazia; however, she is not fully responsible for it. This is so because she does not have the authority to raise or reallocate public resources for the purposes of providing citizens with access to Rotamax. Instead, the government has this authority. Roberts does not therefore have the option of changing the situation so that her proposal would not be a coercive proposal. Instead, she can either (1) adhere to the requirements that hold for DPRIs under ideal conditions and refuse to conduct the trial, perhaps instead using the resources at her disposal for an alternative, though likely less urgent, RCT; or (2) conduct the trial and be complicit in the wrong of making and carrying out a coercive proposal. ${ }^{16}$

Roberts ought to choose the latter option. By doing so, she (1) better complies with the DPRA's mandate, and (2) acts more consistently with the state's duty of distributive justice than if she chooses the former option. Although she is complicit in the wrong of making and carrying out a coercive proposal, and violates the directive of Tazia to not act in a way that is inconsistent with its duty to provide its citizens with Rotamax, conducting rotacheap is nonetheless the all-things-considered most justifiable course of action.

First, the mandate of Tazia's DPRA is to use the resources at its disposal to fund and conduct research that aims to improve the care available to citizens. Developing Rotamin falls under this mandate, since there is no reasonable expectation that Tazia will provide its citizens with Rotamax within a reasonable time frame. One might argue that Tazia's DPRA should reallocate its resources to the provision of care. However, Tazia's DPRA does not have the authority to do so. Although citizens are entitled to Rotamax, they can nonetheless support the DPRA's use of public resources to develop Rotamin, given that it is urgently needed and given that there is no reason to expect the state to provide its citizens with Rotamax. The alternative, after all, is to allow these resources to stay idle or to use them for a less urgent need.

Second, Roberts and the chief officials of the DPRA can justify rotacheap to participating subjects on the grounds that they are treated more justly ex ante by the state as participants in the trial, than outside of the trial. Although rotacheap is inconsistent with full compliance with the state's duty of distributive justice, participating subjects are treated more justly ex ante by the state because they are given a chance at receiving Rotamin, an intervention that promises to be more effective than the intervention they have access to outside of the trial, namely, nothing. The underlying idea here is that compliance with duties of distributive justice is a matter of

\footnotetext{
${ }^{16}$ Note that there might be states that are so unjust that carrying out the mandate of DPRAs is simply not justifiable. I assume here that Tazia meets the minimal conditions of justice such that Tazia's DPRA may permissibly carry out its mandate.
} 
degree. Although Tazia owes its citizens Rotamax, it complies with its duties to a greater degree if it provides them with an effective - though inferior - treatment, than nothing. Similarly, if a higher income state owes its citizens a basic income of $\$ 30,000$, it complies with this duty to a greater extent if it gives them $\$ 25,000$ than $\$ 20,000$.

For this same reason, Tazia is also not in a position to complain about rotacheap. If Tazia had complied with its duties of distributive justice and provided its citizens with access to Rotamax, it would have grounds for complaint if Roberts conducted rotacheap (assume for the moment Roberts could enroll subjects despite the fact that they have access to Rotamax). Tazia has grounds for complaint in this case because Tazia is prepared to fulfill its duties to its citizens and its agent acts in a way that is inconsistent with the fulfillment of these duties. If Tazia does not satisfy its duties of distributive justice, however, as in the case in rotacheap, Tazia has no complaint against Roberts since by conducting the trial, Roberts does a better job of fulfilling Tazia's duties than Tazia. Tazia may not therefore authorize its DPRA to conduct rotacheap; however, if Tazia fails to provide its citizens with Rotamax, it is not in a position to complain if Roberts does so.

Although Roberts is therefore complicit in Tazia's wrongful coercion of her subjects, conducting rotacheap is nonetheless the best choice of action, both from the standpoint of the DPRA's mandate, and from the standpoint of justice. Of course, this does not mean that Roberts need only treat her subjects in a way that is minimally more just than Tazia treats them outside of the trial. Instead, DPRIs should endeavor to treat subjects as justly as possible, given the resources that they have available. ${ }^{17}$ Thus, if Roberts has the funds necessary to do so, she should conduct rotacheap as an active controlled trial, on the condition that doing so meets the standards of scientific validity. ${ }^{18}$

\footnotetext{
${ }^{17}$ There is a further question here concerning the allocation of resources for research. If Roberts has the option of devoting some of the resources she has available to a different, equally urgent study, thus allowing another researcher to provide her subjects with a more just level of care, Roberts should do so since all citizens have a pro tanto equal claim on these resources. If she does not have this option however, she should aspire to provide her subjects with the care they prefer and are entitled to.

${ }^{18}$ One might argue here that there is an additional reason not to conduct rotacheap. Even if Roberts better complies with her institutional obligation by conducting rotacheap than not, if conducting the trial involves coercing her subjects, Roberts may not do so since her subjects' consent to participate would then be invalid. Responding to this objection is beyond the scope of this article, since I am only concerned here to specify the implications of the institutional obligations of investigators, not their natural duties. However, note first that some dispute that such cases of third party coercion invalidate consent. See F.G. Miller \& A. Wertheimer. 2010. Preface to a Theory of Consent Transactions: Beyond Valid Consent. in The Ethics of Consent: Theory and Practice. F.G. Miller \& A. Wertheimer, eds. New York: Oxford
}

Under non-ideal conditions therefore, DPRIs are subject to the following set of institutional obligations:

1. DPRIs may test a novel treatment on human subjects only if either:

a. it is in a state of clinical equipoise with, or known to be superior to, the best treatment that can be reasonably expected to be provided by the government within a reasonable time frame; or

b. subjects autonomously prefer it over the best treatment that can be reasonably expected to be provided by the government within a reasonable time frame.

2. DPRIs ought to provide subjects in the control arm with either:

a. the best treatment that they are legitimately able to provide; or

b. in cases where subjects autonomously reject (2a), the best treatment

i. DPRIs are legitimately able to provide; and

ii. subjects will consent to.

These requirements apply to DPRIs working under both ideal and non-ideal conditions since under conditions of justice, (1a) and (2a) will simply refer to the treatment the state owes to its citizens. ${ }^{19}$

\subsection{Internationally-focused public research investigators}

Internationally-focused public research agencies (IPRAs) are agents of states that have a mandate to fund or conduct research for the purposes of improving care available to foreigners. By carrying out this mandate, IPRAs discharge - in part - the duties of higher income states to aid lower income states. Although some liberal theorists argue that international justice demands more than this, most agree that such a duty to aid is a minimum requirement of justice. Social liberals, who understand international justice to concern the relations amongst states, can support this duty of aid as a specification of the duty of assistance well-ordered states owe to societies burdened by unfavorable political, material, and technological conditions. ${ }^{20}$ Cosmopolitan liberals, who do not

University Press: 79-106. Note second that even if Roberts' subjects' consent is invalid, it still does not necessarily follow that she should not conduct the study. For a discussion of this question see J. Millum. Consent Under Pressure: The Puzzle of Third Party Coercion. Ethical Theory Moral Pract. Forthcoming.

${ }^{19}$ More needs to be said here about what it means to 'reasonably' expect the government to provide a treatment within a 'reasonable' time frame. However, this task is beyond the scope of this article. For a promising account, see A. J. London's conception of 'practical attainability' in A.J. London. 2001. Equipoise and Human-Subjects Research. Bioethics 2001; 15: 312-332.

${ }^{20}$ See J. Rawls. 1999. The Law of Peoples. Cambridge, MA: Harvard University Press: 105-113. 
draw a sharp distinction between domestic and international justice, can also support such a proposal as a minimum requirement of the demands of global distributive justice. ${ }^{21}$

Gopal Sreenivasan develops this point of consensus, arguing that 'any plausible and complete ideal of international distributive justice. . . will at least require betteroff states to transfer one percent of their gross domestic product (GDP) to worse-off states. ${ }^{22}$ I will take Sreenivasan's proposal as a specification of the duty to aid for the purposes of this article. As well as receiving support from liberal theories of justice, a few states comply with this duty (or nearly do so) and others including members of the EU - have pledged to raise their levels of international aid to 0.7 percent of GDP. ${ }^{23}$

I argue that internationally focused public research investigators (IPRIs) are bound by a similar set of institutional obligations as DPRIs. The role of IPRIs is structurally the same as that of DPRIs and so the arguments I discuss in 1.1 apply equally here.

First, IPRIs must conduct their research in a way that is consistent with the sponsoring state's duty of aid. The sponsoring state may not authorize its agents to treat foreigners in a way that is inconsistent with its duties to them. Second, IPRIs must conduct their research in a way that is consistent with the host state's duty of distributive justice, since, on any reasonable understanding of the sponsoring state's duty to aid, it requires that they do so. For social liberals, who understand the duty to aid as a duty that stable higher-income states owe to burdened states, IPRIs are bound by the host state's duty of distributive justice since the goal of these agencies is to enable it to be just and stable. ${ }^{24}$ IPRIs are, in a sense, acting on behalf of the host state, building its institutional capacity and helping it to provide the services it owes to its citizens. For cosmopolitan liberals, who understand the duty of aid as a component of the duties of distributive justice that bind all agents, IPRIs are bound by the host state's duty of distributive justice for the simple reason that it is not essentially distinct from the duty of aid. For these theorists, IPRIs are bound to conduct their research in a way that is consistent with distributive justice, regardless of how the responsibilities for securing distributive justice are allocated amongst different agents.

IPRIs therefore possess the following two institutional obligations:

\footnotetext{
${ }^{21}$ See C.R. Beitz. 1999. Political Theory and International Relations. Princeton: Princeton University Press. For a more in-depth account of the distinction between social and cosmopolitan liberalism see C.R. Beitz. Social and Cosmopolitan Liberalism. Int Aff 1999; 75: 515-529.

${ }^{22}$ G. Sreenivasan. International Justice and Health: A Proposal. Ethics Int Aff 2002; 16: 83.

${ }^{23}$ In 2009, Sweden, Norway, and Luxembourg gave more than one percent of GNI as official development assistance. Denmark (.88) and Netherlands (.82) came close.

${ }^{24}$ See Rawls. op. cit. note 20, pp. 105-113.
}

1. IPRIs may test a novel treatment on human subjects only if either:

a. it is in a state of clinical equipoise with, or known to be superior to, the best treatment that can be reasonably expected to be provided by the government and international community within a reasonable time frame; or

b. subjects autonomous prefer it over the best treatment that can be reasonably expected to be provided by the government and international community within a reasonable time frame.

2. IPRIs must provide subjects in the control arm with:

a. the best treatment that they are legitimately able to provide (given resources and obligations of the host state and sponsoring state); or

b. in cases where subjects autonomously reject (2a), the best treatment:

i. IPRIs are legitimately able to provide; and

ii. subjects will consent to.

The AZT trials of the mid 1990s provide a good case study for spelling out the implications of these institutional obligations. These placebo-controlled trials were sponsored in part by the National Institutes of Health (NIH) and the Centers for Disease Control (CDC) and were conducted in a series of lower income countries in Asia and Africa. They aimed to evaluate the effectiveness of a short-course AZT regimen in preventing the transmission of HIV from mother to child. Although an effective long-course AZT regimen (076) was available in higher income countries at the time, these lower income countries could neither afford nor deliver this regimen by means of their public health system.

From the perspective of the institutional obligations of IPRIs, the key questions concerning the permissibility of the AZT trials concern whether (1) citizens of these countries could reasonably expect to have access to the 076 regimen within a reasonable time frame, and whether (2) they were entitled to it. If the answer to these two questions is yes, then the IPRIs conducting the AZT trials violated their institutional obligations. If the answer is no, they did not. I will not attempt to provide definitive answers to these questions here since much depends on complex empirical circumstances. However, on the basis of some back-of-the-envelope calculations, it is reasonable to conclude that for the countries that participated in these trials, the answer to both of these questions is no. For example, consider South Africa, the wealthiest country in which the AZT trials took place. In 1995, South Africa had a GNI per capita of US $\$ 3740$ (\$5980 PPP current international $\$),{ }^{25}$ and the government spent US $\$ 107$ per capita on

\footnotetext{
${ }^{25}$ The World Bank. 2012. World Databank. Available at: http:// databank.worldbank.org [Accessed 11 Oct. 2012].
} 
health $(39.3 \%$ of US $\$ 273$ per capita total spending on health) ${ }^{26}$ At the time, the 076 regimen cost US $\$ 1,000$ per woman, ${ }^{27}$ and more importantly, was very complex, requiring pregnant women to present in their second trimester, receive the drug intravenously during labour, and forego breastfeeding.

With respect to (1), it is difficult to see how the citizens of South Africa could have reasonably expected the government to provide the 076 regimen to them within a reasonable time frame, given its cost and complexity. The government would have had to not only fund an expensive treatment for $14.07 \%$ of its pregnant women, but also direct substantial resources towards increasing the number of clinical visits for pregnant women and subsidize the distribution of a breast milk substitute. ${ }^{28}$

With respect to (2), it's not clear that the government of South Africa would have been able to afford to provide its citizens with the 076 regiment even if it fully complied with its duties of distributive justice and the international community fully discharged its duty of aid. To see this, suppose that the government of South Africa spent $10 \%$ of its GNI per capita on health - US $\$ 374$ and that higher income countries (those GNI per capita income in 2010 was 12,276 or more) - spent $25 \%$ of its duty to aid (1.0\% of GDP) - US $\$ 24,794,709,768$ - on health care for citizens of low and middle income countries (those whose GNI per capita income in 2010 was US $\$ 12,275$ or less). ${ }^{29}$ South Africa would only have had US $\$ 374$ to spend on each of its citizens, and the higher income countries would only have had US $\$ 13$ for each citizen of low and middle income countries. South Africa would no doubt deserve a greater share of this aid than middle income countries with higher incomes and, because of purchasing power parity considerations, this US $\$ 13$ would be worth more; however, it's still not clear that the 076 regimen would have been affordable. Also, even if South Africa could have afforded to provide its citizens with the 076 regimen under ideal conditions, most of the other countries in which the AZT trials took place could not have done, since their GNI per capita was far lower: Burkina Faso US \$220 (\$570 PPP), Cote d'Ivoire US \$670 (\$1300 PPP), Dominican Republic US \$1910 (\$3490 PPP), Ethiopia US \$150 (\$390 PPP), Kenya US \$270 (\$1030 PPP), Malawi US \$160 (\$490 PPP),

\footnotetext{
${ }^{26}$ World Health Organization. 2012. Global Health Observatory Data Repository. Available at: http://apps.who.int/ghodata/ [Accessed 11 Oct. 2012].

${ }^{27}$ C. Grady. Science in the Service of Healing. Hastings Cent Rep 1998; 28: 35 .

${ }^{28}$ See S.S. Abdool Karim. Placebo Controls in HIV Perinatal Transmission Trials: A South African's Viewpoint. Am J Public Health 1998; 4: $564-565$.

${ }^{29}$ World Bank. op. cit. note 22.
}

Tanzania US \$170 (\$630 PPP), Thailand US \$2720 (\$4550 PPP), Uganda US \$230 (\$540 PPP), Zimbabwe US $\$ 600$ (all figures 1995). ${ }^{30}$

As far as the institutional obligations of IPRIs are concerned therefore, it is reasonable to think that it was permissible for the NIH and CDC to fund and conduct the short course AZT trials. Of course, both here, and in the previous section, my aim has not been to defend a comprehensive account of standard of care. IPRIs might therefore have other obligations that would prohibit them from conducting these trials. For example, one could argue that investigators should have provided subjects in these trials with the 076 regimen on the grounds that investigators have a professional therapeutic obligation to do so, or on the grounds that investigators have a natural duty to rescue.

\subsection{Institutional obligations and distributive justice-based accounts of standard of care}

My account of the institutional obligations of DPRIs and IPRIs contributes to the development of a reasonable distributive justice-based account of standard of care in two ways. First, in contrast to existing accounts, my discussion of institutional obligations provides a strong justification for why investigators must provide subjects with the care they are entitled to as a matter of distributive justice. Existing distributive justice-based accounts, by contrast, fail to motivate this claim. For example, Kukla claims that 'researchers should not run studies unless, to the best of their knowledge, every trial arm receives care that is at least as good as the local de jure standard of care' (where the de jure standard of care is the care individuals are entitled to as a matter of justice). ${ }^{31}$ She derives this standard from the claim that investigators, qua persons, have duties of respect, welfare protection, and justice to their subjects that cannot be compromised for the purposes of research. ${ }^{32}$ However, the former standard follows from the latter claim only if investigators, qua persons, have a positive duty to provide others with the care they are entitled to - a claim that is not argued for and highly contentious. After all, most political philosophers claim that it is the responsibility of institutions - not individuals - to provide citizens with what they are owed, whether access to health care, income, opportunities etc. In the absence of this claim, it only follows that investigators have a negative duty to not prevent their subjects from accessing care that they are entitled to and that is available outside of the trial.

\footnotetext{
${ }^{30}$ Ibid.

${ }^{31}$ Kukla, op. cit. note 7, p. 178.

${ }^{32}$ Ibid: 176-178.
} 
Emanuel's account improves on Kukla's insofar as it recognizes that investigators do not have a responsibility to discharge duties of distributive justice, arguing instead that they must provide their subjects with the care to which they are entitled to ensure that the trial has a favorable risk-benefit ratio. ${ }^{33}$ However, for non-ideal cases, this line of argument only seems to imply that investigators must provide their subjects with the care that is locally available, not the care to which they are entitled. Emanuel rejects this implication, arguing that the risk-benefit ratio must be determined with reference to the care subjects are entitled to. ${ }^{34}$ However, he provides little argument for this claim, only noting that evaluating the risk-benefit ratio by appeal to the actual risks subjects face given the care available to them outside of the trial would make permissible many RCTs that seem prima facie unjust. ${ }^{35}$ However, surely the relevant comparator for a potential subject is the treatment she would actually receive outside of the trial, not the treatment she is entitled to receive.

Second, although Kukla and Emanuel have addressed the problem of what investigators owe to their subjects in non-ideal conditions, arguing that investigators should provide their subjects with the care they are entitled too even if governments do not; ${ }^{36} \mathrm{I}$ don't think their accounts have adequately addressed the question of what investigators ought to do in cases where they simply do not have the resources to do so. For example, may they conduct a RCT (1) that is necessary to develop a promising, affordable intervention, but (2) that requires providing subjects with care that is inferior to the care they are entitled to? Emanuel briefly addresses a similar problem, arguing that investigators may not conduct such a trial unless the social value is great and the resulting intervention could be implemented expeditiously. ${ }^{37} \mathrm{He}$ argues for this position on the grounds that conducting the trial would violate the favorable risk-benefit ratio principle. ${ }^{38}$ However, as I note above, it's unclear why subjects who participate in such trials would face an unfavorable riskbenefit ratio if they do not have access to the treatment in the first place.

Kukla and Emanuel might agree that my account contributes to the development of a reasonable distributive justice-based account of standard of care in the ways that I suggest, but object that it only covers investigators who work for public institutions and not for private-for-profit corporations. In the next part of this paper, I provide an account of why this distinction is an important one.

\footnotetext{
${ }^{33}$ Emanuel, op. cit. note 7, pp. 208-209.

${ }^{34}$ Ibid: 209.

${ }^{35}$ Ibid.

${ }^{36}$ Kukla, op. cit. note 7; Emanuel, op. cit. note 7.

${ }^{37}$ Emanuel, op. cit. note 7.

${ }^{38}$ Ibid.
}

\section{CLINICAL RESEARCH AND PRIVATE-FOR-PROFIT CORPORATIONS}

Not all investigators work under the mandate of public health. Investigators who are employed or sponsored by pharmaceutical corporations operate - at least in part under the mandate of profit-seeking. The primary purpose of such organizations, after all, is to seek profits for their owners, whether these are private parties or shareholders. ${ }^{39}$

Amongst business ethicists, the prevailing account of the obligations of private-for-profit corporations (PFPCs) is stakeholder theory. On this view, managers not only have obligations to shareholders, but also to other 'stakeholders,' including employees, consumers, suppliers, and communities. ${ }^{40}$ In recent years however, a number of commentators have shown that stakeholder theory suffers from a number of serious problems. It does not clearly identify who or what constitutes a stakeholder. ${ }^{41}$ It does not provide an account of how to balance the often conflicting interests of different stakeholders. ${ }^{42}$ And, more fundamentally, it imposes a set of ethical obligations on PFPCs that have a completely different normative rationale from the regulatory obligations supported by economists and often institutionalized in contemporary liberal democracies, suggesting that stakeholder theory fails to recognize the appropriate role of private enterprise within such societies. $^{43}$

For the purposes of understanding the obligations of PFPCs therefore, I shall adopt an account that starts from a broader justification for the market system itself: the market failures approach..$^{44}$ On this account - and in accordance with what I define above as generic liberalism - states may permit the formation of PFPCs and establish markets within which they may compete because free citizens have an interest in the efficient production of

\footnotetext{
${ }^{39}$ Not all research is of course purely private or purely public but is instead carried out in the context of a public-private partnership. This is not a problem for my view however. Public researchers, whether they are collaborating with private-for-profit companies or not, are bound by the institutional obligations that apply to them.

${ }^{40}$ R. Edward Freeman et al. 2010. Stakeholder Theory: The State of the Art. New York: Cambridge University Press: 9.

${ }^{41}$ J. Heath. Business Ethics without Stakeholders. Bus Ethics Q 2006; 16: 544-546; and E.W. Orts and Al. Strudler. Putting a Stake in Stakeholder Theory. J Bus Ethics 2009; 88: 606-608.

${ }^{42}$ Orts and Strudler. op. cit. note 41, 611-612. For an account of the related agency problems that arise from obligating managers to consider the interests of multiple stakeholders, see J. Heath and W. Norman. Stakeholder Theory, Corporate Governance, and Public Management. J Bus Ethics 2004; 53: 247-265.

${ }^{43}$ W. Norman. Business Ethics as Self-Regulation: Why Principles that Ground Regulations Should be Used to Ground Beyond-Compliance Norms as Well. J Bus Ethics 2011; 102: 43-57.

${ }^{44}$ Heath. op. cit. note 41, pp. 547-552.
} 
goods and services. ${ }^{45}$ Market competition amongst PFPCs accomplishes this goal since it ensures that resources are employed as efficiently as possible to satisfy the preferences of consumers. The structure of justification is thus an indirect one - profit-seeking by PFPCs is not itself valuable, but is instead valuable because of the state of affairs that it leads to. ${ }^{46}$ By permitting PFPCs to seek profits, policy-makers introduce competition amongst producers and consumers. Consumers can shop around for the best price and producers can undercut each other by lowering prices. This competition in turn drives the prices of goods and services to the point at which all markets clear - the point at which producers have no unsold products and consumers have no unmet demands. This justification for market competition amongst PFPCs is formalized by the first fundamental theory of welfare economics, according to which such competition secures a Pareto-optimal outcome, that is, an outcome where it is not possible to shift the use of resources to make someone better off without making someone else worse off. ${ }^{47}$

On the market failures account, the role of regulatory and ethical constraints is to prevent market failures, that is, to prevent those situations that fail to produce a Pareto-optimal outcome. ${ }^{48}$ As an approach to business ethics, the basic idea is that PFPCs may seek profits, but only within certain constraints. Since the first fundamental theory of welfare economics only holds under certain conditions - Pareto conditions - profit-seeking behavior is only justifiable if it is consistent with these conditions, including prohibitions on theft and fraud, a requirement of symmetrical information between producer and consumer, and prohibitions on uncompensated negative externalities. ${ }^{49}$ States have a duty to enforce these Paretoconditions, for example, by preventing the formation of anti-competitive monopolies, internalizing negative externalities, reducing asymmetries in information, and passing intellectual property laws - such as the patent system - to deal with free-rider problems. Similarly, because justifiable profit-seeking is limited to behavior that is consistent with Pareto conditions, PFPCs may only engage in profit-seeking strategies that are consistent with these conditions. Pareto conditions therefore define what Christopher McMahon calls 'the implicit morality of the market. ${ }^{50}$

\footnotetext{
${ }^{45}$ J. Heath. 2004. A Market Failures Approach to Business Ethics. In Studies in Economic Ethics and Philosophy, Vol. 9. Dordrecht: SpringerVerlag: 74-77.

${ }^{46}$ Ibid.

${ }^{47}$ Ibid.

${ }^{48}$ Heath. op. cit. note 41, pp. 550-552.

${ }^{49}$ Ibid: $549-550$

${ }^{50}$ Christopher McMahon. Morality and the Invisible Hand. Philos Public Aff 1981; 10: 254.
}

This latter point is important for our purposes because it follows from this that PFPCs are subject to a different set of moral norms than persons - the implicit morality of the market is not identical to those moral norms governing interpersonal conduct. First, PFPCs have obligations that persons do not have. For example, because symmetrical information between producers and consumers is a Pareto condition, PFPCs have a robust duty to tell the truth about their products. ${ }^{51}$ This duty to facilitate the flow of truthful information is stricter than the duties of persons to refrain from deception. ${ }^{52}$ Second, PFPCs do not have obligations that persons have. For example, because rational utility-maximizing behavior is a Pareto condition, PFPCs do not have a duty of beneficence. ${ }^{53}$ This is so because the duty of beneficence places an end on PFPCs - the welfare of others - that is directly at odds with rational utility-maximizing behavior. ${ }^{54}$

One might argue that this latter implication of the market failures approach is worrisome and that managers should not simply aim to maximize profits but should instead aim also to promote the interests of their employees, consumers, and the communities within which they operate as the stakeholder theory suggests. However, in response, it is important to note three things. First, my claim is not that corporations may seek profits simpliciter; rather, it is that they may do so within the constraints of Pareto conditions. They may not engage in profitseeking behavior therefore that involves the imposition of negative externalities or false advertising. They must compete on the basis of price and quality. Second, as I note above, the justification for permitting profit-seeking behavior that is consistent with Pareto conditions appeals to the motivation underlying this objection, namely, that everyone will be better off. Third, the market failures account does not deny that the interests of communities and employees ought to be promoted. Instead, it only denies that it is the responsibility of private corporations to do so directly. As I note above, private corporations do promote these interests indirectly by seeking profits for themselves. Also, since I am committed to generic liberalism, I affirm a large role for the state to play in regulating economic activity and securing distributive justice.

What are the implications of the market failures approach for the ethics of PFPCs-sponsored RCTs? First, investigators who are employed or have their research sponsored by PFPCs - call them for-profit research investigators (FPRIs) - do not have to conduct their research in a way that is consistent with the state's duty of aid or duty of distributive justice. They are not

\footnotetext{
51 Ibid: 257.

52 Ibid: $260-261$.

${ }^{53}$ Ibid: $261-262$.

${ }^{54}$ The claim here is not that PFPCs have a duty to behave as rational utility-maximizers, only that is permissible for PFPCs to do so since rational utility-maximizing behavior is a Pareto-condition.
} 
bound by these institutional obligations since it is not the responsibility of PFPCs to secure distributive justice, nor is it a Pareto-condition. FPRIs - qua agents of PFPCs do not therefore have to ensure that the experimental interventions they test on human subjects are in a state of clinical equipoise with the best treatment that citizens can reasonably expect the government to provide, nor must they endeavor to provide subjects in the control arm with best treatment they are entitled to. Second, it is difficult to see how FPRIs could have any institutional obligations that are (1) derivable from their institutional role and that are (2) relevant to the question of standard of care. Of course, FPRIs do have the same natural duties and professional obligations as DPRIs. FPRIs must therefore comply with those norms that are justified on the basis of natural duties and professional obligations which may include: informed consent, scientific validity, fair subject selection, risk-benefit assessment, and independent institutional review. ${ }^{55}$

To see the implications of the lack of institutional obligations of FPRIs that are relevant for standard of care, consider surfaxin, a case that has received a good deal of critical attention:

Surfaxin: In 2000, Discovery Labs (DL), a US PFPC, proposed to conduct a Phase III trial in Bolivia to demonstrate the efficacy of Surfaxin, a new synthetic surfactant useful for the treatment of respiratory distress syndrome (RDS), a common and potentially fatal disease in premature infants. ${ }^{56}$ At the time, Bolivia (GDP per capita $\$ 2,700$ PPP) did not provide surfactant therapies to premature infants due to its high cost (U.S. $\$ 1,100-2,400$ per child); however, such therapies were approved for use and were available to a privileged minority. ${ }^{57}$ The study would have been two-arm, double-blinded and randomized, and was to involve 650 premature infants with RDS, who would not have otherwise received surfactant therapy (or any other form of effective therapy). ${ }^{58}$ Subjects in the control arm were to be given a placebo by means of a

\footnotetext{
${ }^{55}$ It may also be permissible for states to enact regulatory regimes that require FPRIs to comply with the same standards that apply to DPRIs or IPRIs. FPRIs would then have an obligation to conduct their research in a way that is consistent with the host state's duty of distributive justice and, depending on whether the PFPC is domestic or foreign, the foreign state's duty of aid. In this case however, the obligation in question would be a legal obligation, not an institutional obligation. The source of the obligation would not be the nature of the institutional context within which FPRIs conduct their research, but rather state legislation. Thanks to an anonymous reviewer for suggesting this possibility.

${ }^{56}$ J. Hawkins \& E. Emanuel. 2008. Case Studies: The Havrix Trial and the Surfaxin Trial. In Exploitation and Developing Countries: The Ethics of Clinical Research. J.S. Hawkins \& E.J. Emanuel eds. Princeton: Princeton University Press: 55-62.

${ }^{57}$ Ibid: 59.

${ }^{58}$ Ibid: $60-61$.
}

ventilator, an intervention that is known to improve survival.

Surfaxin is a non-ideal case. Bolivia was not a reasonably just society in 2000 , meaning that its citizens did not have access to the care to which they were entitled as a matter of distributive justice; and higher income countries - including the US - had not fully discharged their duty to aid Bolivia around the time of the trial. ${ }^{59}$ Since DL's investigators are neither DPRIs nor IPRIs, they do not have an obligation to ensure that Bolivia could, within a reasonable time frame, provide its citizens with Surfaxin; nor must they provide subjects in the control arm with an effective surfactant treatment - an obligation DPRIs or IPRIs might have, if Bolivian citizens could be said to be entitled to one. Instead, considering the case solely from the perspective of their lack of institutional obligations, DL's investigators may conduct surfaxin as a PCT. This conclusion, moreover, is consistent with the broader role of PFPCs within liberal democracies. The profit-seeking behavior of PFPCs like DL is justifiable provided it is subject to Pareto-conditions - because it leads to a Pareto-superior use of resources. States may therefore permit the formation of PFPCs and establish markets - both domestic and international - within which they may operate since doing so allows agents to make Pareto-improving transactions. Surfaxin is an example of this process at work. Because Bolivia had a much weaker healthcare system than many higher income countries at the time, DL had an incentive to conduct an RCT evaluating Surfaxin in Bolivia since it could conduct the trial as a PCT rather than as a much more expensive ACT in a higher income country. The former is Pareto superior in two ways. First, a good number of Bolivian infants would have received surfactant therapy that they otherwise would not have received. By contrast, had the trial been conducted as an ACT in a higher income country, no additional infants would have received this therapy - all would have received it outside of the trial simply as a matter of course. Second, by conducting the trial as a PCT, DL eliminates costs, which - assuming a reasonably functioning market - could have been passed on to consumers in the form of lower prices, or reinvested in the firm to develop other treatments.

Of course, as I note above, my account of the institutional obligations of investigators - or lack thereof in the case of FPRIs - is not intended to be a comprehensive

\footnotetext{
${ }^{59}$ There is an additional question here concerning whether DL is entitled to operate in Bolivia. My own view on this is that because the US has a duty to aid Bolivia, it may only permit US-based corporations to operate in Bolivia if doing so is consistent with this duty. The idea here is not that DL must make the wellbeing of Bolivians its goal but rather that the US government has a duty to permit only types of trade with Bolivia that further the overall goal of eradicating poverty in Bolivia. For the purposes of this article, I will assume that the terms under which DL planned to operate in Bolivia satisfied this condition.
} 
account of the ethics of RCTs. Since DL and its investigators are no doubt subject to other obligations - including natural duties and professional obligations - which require subject protections - e.g. informed consent and favourable risk-benefit ratio - and have implications for standard of care, it might turn out that trials like surfaxin are impermissible, even though they promise a Paretosuperior state of affairs. ${ }^{60}$

Some will no doubt object to the market failures approach that I have adopted here on the grounds that it imposes norms on PFPCs that are too minimal. Even if one remains committed to the stakeholder view however, one should still welcome my broader point, namely that the obligations of investigators are partly dependent on the institutional context within which they work. Proponents of the stakeholder theory can recognize that investigators possess such obligations, even if they think they are different from those supported by the market failures approach.

\section{CONCLUSION}

My aim in this article has been to contribute to the development of a distributive justice-based account of standard of care. I have sought to address two weaknesses with existing accounts by introducing an account of the institutional obligations - or lack thereof - of public and private investigators. My account of these obligations provides a justification for why public

\footnotetext{
${ }^{60}$ For example, J. Hawkins appeals to the duty to rescue to argue that in cases like surfaxin, investigators wrong their subjects by providing them with a placebo, not an effective treatment. See Hawkins, op. cit. note 3. T. Pogge argues that such trials are wrongful because they involve taking advantage of injustice. See T. Pogge. 2008. Testing our Drugs on the Poor Abroad. In Exploitation and Developing Countries: The Ethics of Clinical Research. J.S. Hawkins \& E.J. Emanuel, eds. Princeton: Princeton University Press: 105-141. One might also argue that such trials are wrongful because they violate investigators' natural duty not to exploit others.
}

research investigators - DPRIs and IPRIs - and not merely institutions are bound by distributive obligations. My account also provides a principled basis for determining when public research investigators - working under non-ideal conditions - may test a novel intervention on subjects and what they must provide to those in the control arm.

Although these points do not extend to private research investigators, I do not regard this as a problem for my view. For as I argued above, I am not convinced that these investigators or their sponsoring corporations should be bound by such obligations given their legitimate role in bringing about Pareto-superior states of affairs. Whether or not I am right about that, the fundamental point remains: we cannot develop an adequate account of the obligations of investigators without attending to the obligations they acquire by virtue of working for specific institutions.

\begin{abstract}
Acknowledgements
I thank Robyn Bluhm, Kirstin Borgerson, Danielle Bromwich, Michael Garnett, Christine Grady, Joseph Millum, Vida Panitch, Tina Rulli, Seema Shah, Alan Wertheimer, and three anonymous reviewers for this journal for helpful comments on earlier drafts of this paper. For their helpful feedback, I also thank audiences at the Department of Bioethics, National Institutes of Health, New Scholars in Bioethics Second Annual Symposium, the Department of Public Policy, University of North Carolina, Chapel Hill, and the Department of Philosophy, SUNY Binghamton.
\end{abstract}

Disclaimer: The opinions expressed here are the author's and do not reflect the policies and positions of the National Institutes of Health, the US Public Health Service, or the US Department of Health and Human Services.

Douglas MacKay is an Assistant Professor in the Department of Public Policy at the University of North Carolina, Chapel Hill, and a Core Faculty Member of the UNC Center for Bioethics. He recently completed a post-doctoral fellowship in the Department of Bioethics at the National Institutes of Health, where he completed much of the research for this article. His research concerns issues at the intersection of distributive justice and bioethics, including international research ethics and priority setting. 